\title{
What is the impact of birth weight corrected for gestational age on later onset asthma: a meta-analysis
}

\author{
Jingjing Wang, Zeyi Zhang and Ou Chen ${ }^{*}$
}

\begin{abstract}
Background: Asthma is a common multifactorial disease affecting millions worldwide. The Barker hypothesis postulates an association between later onset disease risk and energy exposure in utero. Birth weight corrected for gestational age is better for measuring the infant size, which reflects energy exposure in utero. Findings on asthma and birth weight corrected for gestational age have been inconclusive. We conducted a meta-analysis to further clarify the relationship between birth weight corrected for gestational age and later onset asthma.

Methods: A systematic literature search of the PubMed, Web of Science, MEDLINE, and Scopus databases up to January 2021 was conducted. The subject terms were used as follows: "asthma," "allerg*", "respiratory", "birth weight", "gestational age", "birth outcomes", "intrauterine growth retardation", and "fetal growth restriction".

Results: We included 12 articles with data from a total of 6,713,596 people. Compared with non-SGA infants, infants small for gestation age (SGA) were not associated with an increased risk of asthma ( $\mathrm{OR}=1.07 ; 95 \% \mathrm{Cl} 0.94-1.21)$. However, in the subgroup analysis, we found an increased risk of later onset asthma among SGA in studies conducted in Asia, with a large sample size, and defined asthma through medical records rather than questionnaires. Large for gestational age (LGA) was not associated with an increased risk of asthma when non-LGA or appropriated for gestational age (AGA) infants were used as the reference $(\mathrm{OR}=1.02 ; 95 \% \mathrm{Cl} 0.90-1.16$; $\mathrm{OR}=1.01 ; 95 \% \mathrm{Cl} 0.88-1.15)$.
\end{abstract}

Conclusion: These results indicated that neither SGA nor LGA was associated with an increased risk of asthma. However, considering the limitations of the research, these results should be interpreted with caution.

Keywords: Asthma, Birth weight, Gestational age, Small for gestational age, Large for gestational age

\section{Background}

Asthma is a common multifactorial disease affecting millions worldwide [1]. Its etiology is increasingly attributed to interactions between genetic predisposition, host factors, and environmental exposures [2]. The evidence supports the hypothesis that environmental changes play a significant role in the current asthma epidemic. Environmental triggers may affect asthma

*Correspondence: chenou@sdu.edu.cn

School of Nursing and Rehabilitation, Shandong University, NO.44,

Wenhua West road, Jinan, Shandong, China differently during different times of a person's life, and the relevant risk factors may change over time [3].

However, most studies assessing risk factors for asthma development have been limited to life events that occur long after birth. Humans are influenced by various environmental factors from the moment of conception [4]. The Barker hypothesis postulates that an important component of adult disease risk is determined in utero, with maternal nutrition playing an important role [5]. Size for gestational age at birth reflects energy exposure and transfer and the placental function during pregnancy [6]. Barker et al. also implicated an association between birth weight and later respiratory disease original author(s) and the source, provide a link to the Creative Commons licence, and indicate if changes were made. The images or other third party material in this article are included in the article's Creative Commons licence, unless indicated otherwise in a credit line to the material. If material is not included in the article's Creative Commons licence and your intended use is not permitted by statutory regulation or exceeds the permitted use, you will need to obtain permission directly from the copyright holder. To view a copy of this licence, visit http://creativecommons.org/licenses/by/4.0/. The Creative Commons Public Domain Dedication waiver (http://creativeco mmons.org/publicdomain/zero/1.0/) applies to the data made available in this article, unless otherwise stated in a credit line to the data. 
[5]. Subsequently, many studies have examined the relationship between asthma and birth weight, but the conclusions were inconsistent. Recently, a meta-analysis reported an increased risk of childhood asthma with low birth weight (LBW), while high birth weight (HBW) was not associated with an increased risk of asthma [7].

However, a major limitation of many of these studies was that they did not consider the gestational age of the infants. LBW may be a proxy for prematurity, which is an independent risk factor for respiratory morbidity in childhood [8]. Therefore, birth weight corrected for gestational age (BW/GA) is better for measuring infant size and predicting long-term health concerns. Being small for gestational age (SGA) or large for gestational age (LGA) has been associated with adverse neonatal and infant outcomes and developmental outcomes during childhood and beyond [9-11]. Some researchers have found that both SGA [12,13] and LGA [14] are associated with an increased risk of later asthma. However, some researchers reported $\mathrm{BW} / \mathrm{GA}$ had little effect on later asthma $[15,16]$. Therefore, the objective of our metaanalysis was to estimate the direction and magnitude of the impact of BW/GA on later asthma.

\section{Methods}

\section{Literature sources}

We performed a literature retrieval including the databases PubMed, Web of Science, MEDLINE, and Scopus using the terms "asthma", "allerg", "respiratory", and "birth weight", "gestational age", "birth outcomes", "intrauterine growth retardation", and "fetal growth restriction" in the title. The search was conducted through January 2021.The references of the literature selected for the present study were also examined to improve the recall rate.

\section{Study inclusion and exclusion criteria}

To be eligible, a study must meet the following criteria: it must have been an original document assessing the relationship between $\mathrm{BW} / \mathrm{GA}$ and asthma, and there were sufficient data to calculate the required results. In addition, BW/GA should be reported in categories within accepted ranges (e.g., SGA, infants with a birth weight below the 10th percentile for GA; appropriate for gestational age (AGA), birth weight between the 10th and 90th percentile for GA; LGA, birth weight above the 90th percentile for GA). The reasons for exclusion were as follows: (1) if the paper was a review or comment; (2) if the full text could not be obtained; (3) it was a duplicate.

\section{Primary variables}

The primary outcome was asthma and the diagnosis was obtained from medical records or questionnaires in all included studies. The main exposure was BW/GA, including SGA, AGA, LGA.

\section{Study selection}

First, two reviewers screened the literature by reading titles and abstracts independently. Then, they read the full text to determine whether the previously selected articles fulfilled the inclusion criteria. They were included in the meta-analysis if they fulfilled the eligibility criteria. If there were discrepancies between the reviewers, the inclusion or exclusion of the article was decided by the third reviewer.

\section{Evaluation of study quality}

The Newcastle-Ottawa instrument recommended by the Cochrane Collaboration was used to assess the quality of the included cohort and case-control studies. It contains eight questions in three areas: selection, comparability, outcome or exposure. The article receives a star when it meets one term criterion, and the criteria for the grades of study quality are (1) low quality-when the article gets no more than 3 stars, (2) moderate quality-gets 4 to 6 stars, and (3) high quality-gets 7 to 9 stars. The cross-sectional study appraisal tool developed by the Joanna Briggs Institute (JBI) was used to assess the crosssectional studies and it contains eight evaluation items. Studies were assessed based on the subjects, diseases, the measurement of influencing and confounding factors and the data analysis. The reviewers use "yes", "no", "unclear" or "unsuitable" for judging each item.

\section{Data extraction}

Data were extracted from the included studies by two researchers separately and then they were cross-checked. The data contained the following fields: author's name, year of publication, country of origin, study design, characteristics of the participants, and the outcomes.

\section{Data analysis}

Statistical analysis was conducted using STATA 14.0. The odds ratio (OR) was used as the measure for dichotomous outcomes, and the 95\% confidence interval (CI) for each outcome was estimated to reflect the uncertainty of the point estimates. The unadjusted risk estimates were calculated only when the adjusted risk estimates were unavailable. The effect model for the statistical calculation was selected according to the heterogeneity. Statistical heterogeneity was assessed by chi-square test and it was combined with the I-squared $\left(\mathrm{I}^{2}\right)$ value to quantitatively judge the heterogeneity. A fixed-effects model was applied when there was no significant heterogeneity $\left(I^{2} \leq 50 \%\right)$. Otherwise, the random-effects model was used $\left(I^{2}>50 \%\right)$. Subgroup 
analyses and sensitivity analysis were applied to explore the potential sources of heterogeneity, and the latter was also performed to assess the robustness of the results. Publication bias was evaluated by using Egger's test [17].

\section{Results}

\section{Selected studies}

A total of 2508 articles were retrieved from the databases. After excluding duplicates and reading the titles and abstracts, 32 articles were selected for full-text reading. Only 12 articles with a total of 6,713,596 people met the inclusion criteria and were included in this meta-analysis (Fig. 1). The years of publication for the included studies were 2002 to 2019.

\section{Basic characteristics and the quality of the studies}

Among the 12 articles, there were 6 cross-sectional studies, 5 cohort studies and 1 case-control study. Twelve articles reported fourteen original studies (Gessner [12] divided subjects into two groups according to age; Lu [18] counted two sets of data based on different ways of obtaining the diagnosis of asthma) and they were included in the meta-analysis. Five articles [13,
$15,16,19,20]$ provided adjusted risk estimates, and we used the ORs and 95\% CIs to combine the effect sizes. Cohort and case-control articles were assessed as high-quality studies, while most of the cross-sectional papers did not describe the exclusion criteria or the demographic characteristics of the subjects (Tables 1 and 2). The general characteristics of the studies are shown in Table 3.

\section{BW/GA and risk of asthma SGA and asthma}

Twelve studies [12-16, 18-22, 24] provided data on the asthma prevalence in subjects with SGA compared with non-SGA subjects. We conducted a cumulative meta-analysis according to the publication year. Data from these studies were pooled using the randomeffects model $\left(I^{2}=88 \%, P=0.032\right)$, and the results from this analysis revealed that infants with SGA were not associated with an increased risk of later onset asthma $(\mathrm{OR}=1.07$; 95\% CI 0.94-1.21) (Fig. 2).

Seven studies [12, 14-16, 21, 24] reported the effects of SGA on childhood asthma (under the age of 14), and our pooled result $(\mathrm{OR}=0.90 ; 95 \% \mathrm{CI} 0.66-1.22)$ showed

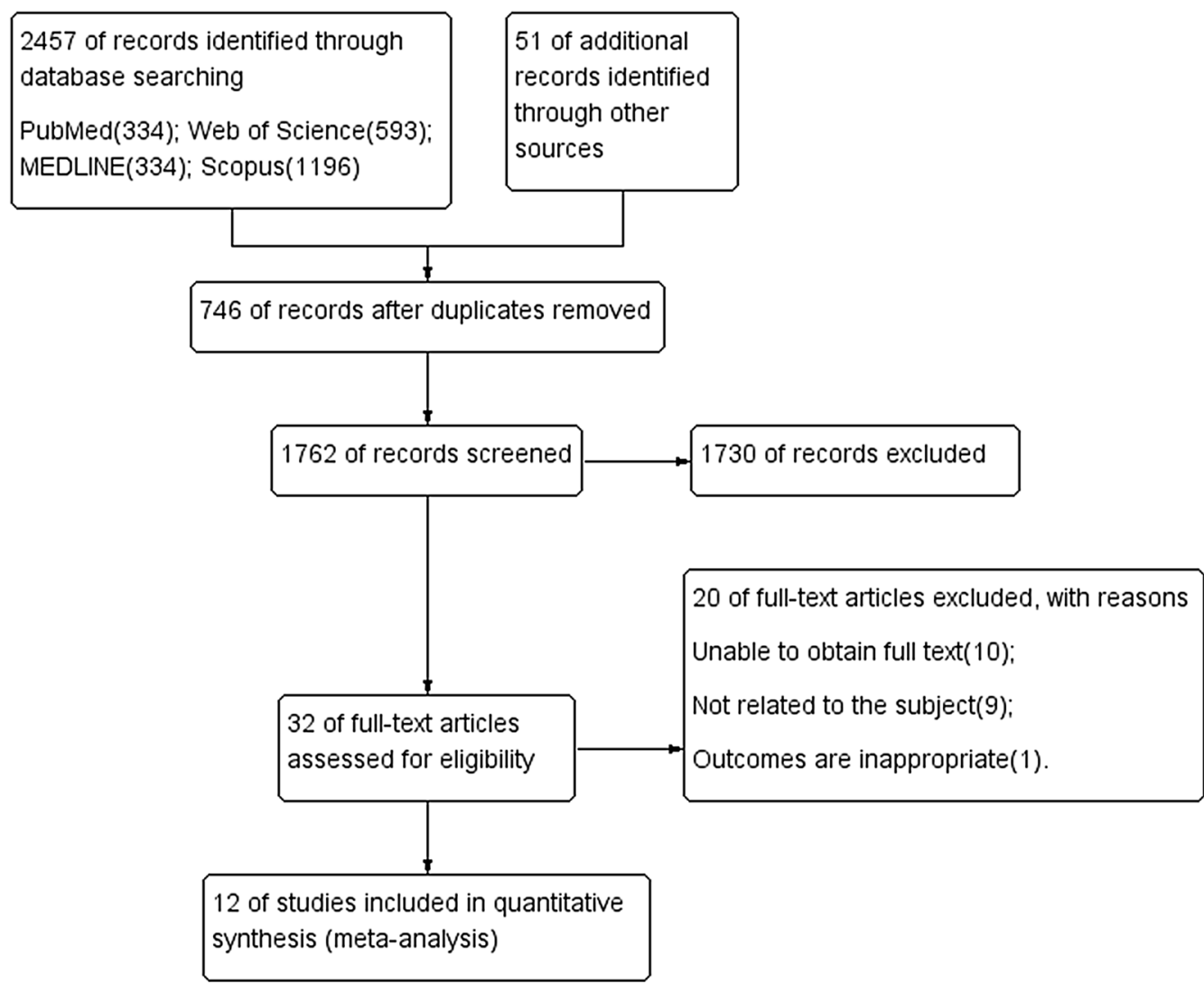

Fig. 1 References searched and selection of articles in the meta-analysis 
Table 1 Assessment of the case-control and cohort study quality

\begin{tabular}{|c|c|c|c|c|c|c|c|c|c|c|}
\hline \multirow[t]{2}{*}{ Studies } & \multicolumn{4}{|c|}{ Selection } & \multicolumn{2}{|c|}{ Comparability } & \multicolumn{3}{|c|}{ Outcome/Exposure } & \multirow[t]{2}{*}{ Score } \\
\hline & 1 & 2 & 3 & 4 & $5 a$ & $5 b$ & 6 & 7 & 8 & \\
\hline Hesselmar et al. [19] & * & & * & * & * & & * & * & * & $* * * * * *$ \\
\hline Grischkan et al. [21] & * & * & * & * & & & & * & * & $* * * * *$ \\
\hline $\begin{array}{l}\text { Jaakkola and Gissler } \\
\text { [16] }\end{array}$ & * & * & * & * & * & & * & * & * & $* * * * * * *$ \\
\hline Liu et al. [22] & * & * & * & & * & & * & * & * & $* * * * * * *$ \\
\hline Pinto et al. [23] & * & * & * & * & * & & & * & * & $* * * * * *$ \\
\hline Carter et al. [13] & * & * & * & * & * & & * & * & * & $* * * * * * *$ \\
\hline
\end{tabular}

For cohort studies, 1, representativeness of the exposure group; 2, representativeness of the non-exposed group 3, determination of exposure; 4, interesting outcome not present in the beginning; $5 \mathrm{a}$, controlling the most important factor; $5 \mathrm{~b}$, controlling any factors; 6 , determination of the outcome; 7 , long follow up until the outcomes to appear; 8 , integrity of the study follow-up

For case-control studies, 1, appropriate case identification; 2 , cases are representative; 3, appropriate source of the control group; 4, no targeted medical history in the control group; $5 \mathrm{a}$, confounding of the most important factors; $5 \mathrm{~b}$, confounding of any factors; 6 , appropriate determination of the exposure factors; 7 , determination that the exposure factors are the same in both groups; 8 , no response rates

*The article meets this term criterion

Table 2 Assessment of the cross-sectional study quality

\begin{tabular}{llllllll}
\hline Studies & $\mathbf{1}$ & $\mathbf{2}$ & $\mathbf{3}$ & $\mathbf{4}$ & $\mathbf{5}$ & $\mathbf{6}$ & $\mathbf{7}$ \\
\hline $\begin{array}{l}\text { Gessner and Chimonas } \\
\text { [12] }\end{array}$ & No & Yes & Yes & Yes & Yes & Yes & Yes \\
Lu et al. [18] & No & Yes & Yes & Yes & Yes & Yes & Yes \\
Wang et al. [20] & No & No & Yes & Yes & Yes & Yes & Yes \\
Kalen et al. [14] & No & No & Yes & Yes & Yes & Yes & Yes \\
Koshy et al. [24] & No & No & Yes & Yes & Yes & Yes & Yes \\
Miyake and Tanaka [15] & No & No & Yes & Yes & Yes & Yes & Yes
\end{tabular}

For cross-sectional studies, 1 , inclusion criteria of subjects; 2 , describe the study subjects and site; 3 , assessment of exposure factors; 4 , assessment of health problems; 5 , clarification of confounding factors; 6 , control confounding factors; 7 , evaluation of outcome indicators; 8 , appropriate data analysis methods

Table 3 Characteristics of the 12 studies included in the meta-analysis

\begin{tabular}{|c|c|c|c|c|c|c|c|}
\hline Author, publication year & Country & Study design & $\begin{array}{l}\text { Total } \\
\text { number of } \\
\text { subjects }\end{array}$ & Age & Asthma definition & $\mathrm{BW} / \mathrm{GA}$ & Gestational age \\
\hline Hesselmar et al. [19], 2002 & Sweden & Case-control & 950 & $15-25 y$ & Questionnaire & SGA & - \\
\hline Grischkan et al. [21], 2004 & American & Cohort & 251 & $8-11 y$ & Questionnaire & SGA & $24-36 w$ \\
\hline $\begin{array}{l}\text { Jaakkola and Gissler } \\
{[16], 2004}\end{array}$ & Finland & Cohort & 58,841 & $0-7 y$ & Medical record & SGA & - \\
\hline $\begin{array}{l}\text { Gessner and Chimonas } \\
{[12], 2007}\end{array}$ & American & Cross-sectional & 37,349 & $<10 y$ & Medical record & SGA & - \\
\hline Lu et al. [18], 2012 & Taiwan & Cross-sectional & 75,181 & $10-17 y$ & $\begin{array}{l}\text { Medical record and } \\
\text { Questionnaire }\end{array}$ & SGA; AGA; LGA & - \\
\hline Wang et al. [20], 2012 & Taiwan & Cross-sectional & 78,011 & $13-16 y$ & Questionnaire & SGA & - \\
\hline Kalen et al. [14], 2013 & Sweden & Cross-sectional & 763,666 & $2-11 y$ & Medical record & SGA; AGA; LGA & $23-44 w$ \\
\hline Koshy et al. [24], 2013 & UK & Cross-sectional & 6361 & $5-11 y$ & Questionnaire & SGA & $39-41 w$ \\
\hline $\begin{array}{l}\text { Miyake and Tanaka [15], } \\
2013\end{array}$ & Japanese & Cross-sectional & 2004 & $3 y$ & Questionnaire & SGA & - \\
\hline Liu et al. [22], 2014 & $\begin{array}{l}\text { Sweden } \\
\text { Finland } \\
\text { Denmark }\end{array}$ & Cohort & $5,656,507$ & $3-18 y$ & Medical record & SGA; LGA; AGA & $22-45 w$ \\
\hline Pinto et al. [23], 2017 & Netherlands & Cohort & 1608 & $8 y$ & Questionnaire & LGA & $38-42 w$ \\
\hline Carter et al. [13], 2019 & Canada & Cohort & 32,867 & $0-25 y$ & Medical record & SGA; LGA; AGA & $\geq 37 w$ \\
\hline
\end{tabular}

BW/GA birth weight corrected for gestational age, SGA small for gestational age, AGA appropriate for gestational age, $L G A$ large for gestational age, $y$ year, $w$ week 


\begin{tabular}{|c|c|c|c|}
\hline Study & & & $\%$ \\
\hline \multicolumn{2}{|l|}{ ID } & ES $(95 \% \mathrm{Cl})$ & Weight \\
\hline & i & \multirow{2}{*}{$0.87(0.56,1.35)$} & \multirow{2}{*}{5.04} \\
\hline & \multirow{2}{*}{$\mid \begin{array}{l}1 \\
1 \\
1\end{array}$} & & \\
\hline Grischkan, J. (2004) & & $0.48(0.24,0.98)$ & 2.58 \\
\hline Jaakkola, J. J. (2004) & & $0.92(0.66,1.30)$ & 6.71 \\
\hline Gessner, B. D. (5-9y) (2007) & + & $1.00(0.78,1.28)$ & 8.65 \\
\hline Gessner, B. D. (<5y) (2007) & $\longrightarrow$ & $1.31(1.05,1.62)$ & 9.38 \\
\hline Lu, F. L. (2012) & + & $1.16(1.04,1.28)$ & 11.92 \\
\hline Wang, W. H. (2012) & 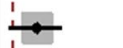 & $1.17(1.05,1.30)$ & 11.86 \\
\hline Kallen, B. (2013) & $\infty$ & $1.43(1.34,1.52)$ & 12.56 \\
\hline Koshy, G. (2013) & & $0.32(0.20,0.53)$ & 4.43 \\
\hline Miyake, Y. (2013) & 4 & $1.04(0.55,1.84)$ & 3.27 \\
\hline Liu, X.2014 (2014) & $1 \rightarrow$ & $1.32(1.14,1.54)$ & 10.95 \\
\hline Carter, J. H. (2019) & $\rightarrow$ & $1.07(1.02,1.14)$ & 12.65 \\
\hline Overall (I-squared $=87.8 \%, p=0.000)$ & & $1.07(0.94,1.21)$ & 100.00 \\
\hline NOTE: Weights are from random effects analysis & i & & \\
\hline $\begin{array}{l}1 \\
2\end{array}$ & & & \\
\hline
\end{tabular}

Table 4 Results of the meta-analysis

\begin{tabular}{lllll}
\hline Meta-analysis & $\begin{array}{l}\text { Number } \\
\text { of } \\
\text { studies }\end{array}$ & $\boldsymbol{I}^{\mathbf{2}}$ & Model & OR $(\mathbf{9 5} \% \mathrm{Cl})$ \\
\hline $\begin{array}{l}\text { SGA vs. non-SGA } \\
\text { (<14y) }\end{array}$ & 7 & $89.30 \%$ & Random & $0.90(0.66-1.22)$ \\
$\begin{array}{l}\text { SGA vs. non-SGA } \\
\text { (GA }>36 w)\end{array}$ & 4 & $91 \%$ & Random & $0.98(0.79-1.23)$ \\
SGA vs. AGA & 5 & $95 \%$ & Random & $1.08(0.89-1.32)$ \\
LGA vs. non-LGA & 5 & $89 \%$ & Random & $1.02(0.90-1.16)$ \\
LGA vs. AGA & 4 & $92 \%$ & Random & $1.01(0.88-1.15)$ \\
\hline
\end{tabular}

$S G A$ small for gestational age, $A G A$ appropriate for gestational age, $L G A$ large for gestational age, $y$ year, $w$ week

that SGA did not increase the risk of childhood asthma when compared with non-SGA. We also found that fullterm (GA > 36 weeks) infants with SGA [13, 14, 22, 24] were not associated with an increased risk of later onset asthma $(\mathrm{OR}=0.98$; 95\% CI 0.79-1.23) (Table 4).
Table 4 also shows the impact of SGA on later onset asthma compared with AGA infants [13, 14, 18, 22, 24]. A random-effects model was used to calculate the effect size, and the results revealed that infants with SGA did not have an increased later asthma risk $(\mathrm{OR}=1.08$; $95 \%$ CI 0.89-1.32).

\section{LGA and asthma}

Non-LGA [13, 14, 18, 22, 23] and AGA [13, 14, 18, $22]$ were used as the reference categories to assess the increased risk of asthma in subjects with LGA. The random-effects model was used to calculate the effect size $\left(I^{2}=89 \%, P=0.015 ; I^{2}=92 \%, P=0.015\right)$, and the pooled estimates revealed no association between LGA and an increased risk of later onset asthma $(\mathrm{OR}=1.02$, 95\% CI $0.90-1.16 ; \quad O R=1.01, \quad 95 \%$ CI $0.88-1.15$ ) (Table 4).

\section{Subgroup analyses}

Subgroup analyses of SGA compared with non-SGA were stratified by study design, study sites, sample size, 
Table 5 SGA vs. non-SGA: the subgroup analysis

\begin{tabular}{llllll}
\hline Stratification & & Number of studies & $\boldsymbol{I}^{\mathbf{2}}$ & Model & OR (95\% Cl) \\
\hline Overall & & 12 & $87.80 \%$ & Random & $1.07(0.94-1.21)$ \\
Study design & Case-control & 1 & - & Random & $0.87(0.56-1.35)$ \\
& Cohort & 5 & $76.60 \%$ & Random & $1.05(0.86-1.29)$ \\
Cross-sectional & 6 & $88.80 \%$ & Random & $1.08(0.91-1.29)$ \\
Study site & Europe & 5 & $91.20 \%$ & Random & $0.94(0.69-1.28)$ \\
& North America & 4 & $65.10 \%$ & Random & $1.06(0.88-1.27)$ \\
Sample size & Asia & 3 & $0 \%$ & Random & $1.16(1.08-1.25)^{*}$ \\
& $<5000$ & 3 & $30.7 \%$ & Random & $0.80(0.54-1.18)$ \\
& $5000-10,000$ & 1 & - & Random & $0.32(0.20-0.52)^{*}$ \\
& $10,000-50,000$ & 3 & $43.20 \%$ & Random & $1.10(0.98-1.25)$ \\
Asthma definition & $50,000-100,000$ & 3 & $0 \%$ & Random & $1.15(1.07-1.24)^{*}$ \\
& $>100,000$ & 2 & $0 \%$ & Random & $1.41(1.33-1.50)^{*}$ \\
& Questionnaire & 5 & $87.50 \%$ & Random & $0.72(0.43-1.20)$ \\
Medical record & 7 & $88.70 \%$ & Random & $1.19(1.04-1.35)^{*}$ \\
\hline
\end{tabular}

$S G A$ small for gestational age

*P $<0.05$

and methods of obtaining the diagnosis of asthma to investigate the potential sources of heterogeneity. The results of the subgroup analyses revealed that SGA was associated with an increased risk of asthma in studies conducted in Asia, with sample sizes ranging from 50,000 to 100,000 and more than 100,000 , and they defined asthma through medical records. The sample size could probably be regarded as the source of the heterogeneity between studies (Table 5).

\section{Sensitive analysis}

Sensitive analyses were conducted for the above six outcomes. We found that the results were robust, except for the outcome of the risk of asthma in subjects with SGA compared with those with non-SGA when the gestational age was greater than 36 weeks. Koshy, G. may be the source of heterogeneity in this outcome.

\section{Publication bias}

Examination of the included investigations did not show a significant effect of publication bias. We assessed the potential publication bias by applying Egger's test, and it was not statistically significant $(P=0.15)$.

\section{Discussion}

In the present meta-analysis, 12 articles reporting 14 original studies with 6,713,596 subjects were included. By conducting a systematic review, we estimated that there was no association between BW/GA and an increased risk of later asthma. After removing the studies of Grischkan [21], Koshy [24], and Miyake [15], the cumulative meta-analysis showed that the estimate gradually became consistent, revealing that SGA was associated with an increased risk of asthma when nonSGA was used as the reference, and the corresponding CIs narrowed down in the order of publication year. In the subgroup analyses, the effects of SGA on asthma were statistically significant in Asia, those with a large sample size, and those defined asthma through medical records.

SGA is defined as infants with a birth weight below the 10th percentile for GA or below 2 S.D. of the reference population mean for BW/GA, which is different from the preterm or LBW population [25]. SGA infants are divided into two categories: SGA infants with normal constitution and SGA infants who have a birth weight lower than the expected optimal birth weight because of growth restriction [26]. The former has a normal birth weight less than the 10th percentile because of inherent factors such as maternal height, weight, ethnicity, and parity, and among these infants, there is no increased risk of perinatal mortality or morbidity, while the latter has a higher risk of mortality and morbidity during the neonatal period and beyond [27]. There are many possible reasons to explain the later result. Children born with fetal growth restriction (FGR) have a greater risk of developing bronchopulmonary dysplasia [28], which is associated with childhood asthma [29], providing a potential mechanism by which SGA increases the risk of asthma [22]. Moreover, factors leading to FGR may also cause "programming" of the respiratory or immune system [30], predisposing SGA infants to develop asthma. Most of the articles we included did not specify which group of SGA was used, perhaps misclassification makes the result meaningless. 
Some studies found that SGA was strongly associated with an increased risk of asthma only when subjects were stratified by certain factors, such as maternal smoking16, lower respiratory infection [12], and childhood overweight [18]. These results are consistent with the theory of perinatal synergistic mechanisms $[16,31,32]$, which suggests that perinatal factors alone have little or no effect on the development of asthma or confer only a slight increase in risk. But if there are associated risk factors, such as prematurity plus maternal smoking during pregnancy, the risk for asthma is notably increased. However, the number of such articles was so low that we could not carry out a meta-analysis.

Subgroup analysis for the sample size showed low heterogeneity among the subgroups, and SGA became a risk factor for asthma when the sample size was more than 50,000. A large sample size is more representative, and a more accurate estimation can be obtained to improve the accuracy of the results. In the forest plot, the 95\% CIs for large samples were narrower. A twin study showed that low birth weight is associated with adultonset asthma, and the analysis suggested that the findings were unlikely to be confounded by genetic or shared environmental factors [33]. Therefore, the association between SGA and an increased risk of later asthma may be influenced by the asthma phenotype. The composition of the asthma phenotype varies in different regions, thus subgroup analysis according to region produced inconsistent results. Further research can focus on the phenotype to explore the relationship between BW/GA and asthma. In the sensitivity analysis of SGA versus non-SGA (GA > 36 weeks), we found that Koshy [24] may be the source of heterogeneity, which estimates SGA as a protective factor for asthma. Compared with the other three articles, this may be because only children between 39 and 41 weeks of gestational age were included, and the asthma definition used a questionnaire.

Studies on the relationship between LGA and asthma were contradictory; some articles found no correlation [22, 23], while some reported a positive correlation [14] and suggested LGA infants have a higher risk of later obesity, which is an obvious risk factor for asthma. In the present meta-analysis we found that LGA was not associated with an increased risk of asthma when infants with non-LGA or AGA were used as reference. This conclusion is consistent with a previous systematic review on the relationship between HBW and asthma. The possible reasons for the meaningless results are as follows [7]. Infants with LGA are associated with an increased risk of overweight in childhood and adulthood [34-36]. Overweight is an independent risk factor for asthma [37, 38]. However, LGA may have no direct effect on later asthma after controlling for confounders. Unfortunately, the studies included in our research did not distinguish the effect of LGA on childhood asthma and adult asthma. These results should be prudently treated because only a small number of studies were included.

Several limitations of this meta-analysis should be considered. First, half of the included articles were cross-sectional, which could not provide a direct causal link between BW/GA and asthma. However, most of these studies had a large sample size, and the findings in cross-sectional studies were consistent with those in cohorts. Second, many studies did not provide a specific gestational age, which may be a potential source of bias in the present article. Preterm birth is associated with LBW, which is a risk factor for asthma. However, we found that the outcomes in full-term infants with SGA were consistent with those in infants unrestricted gestational months. Furthermore, the diagnosis of asthma in young children is considered less accurate because of its clinical instability in the early years of life [22]. Last, the effect of BW/GA on asthma was not the primary objective of most of the identified studies, possibly leading to missing relevant data that were not evident in the title or abstract. These limitations must be noted, and the results should be considered with caution.

\section{Conclusion}

Generally, this meta-analysis showed that infants with SGA or LGA were not associated with an increased risk of later asthma. Additional stratified analyses need to be published to explore the effect of perinatal synergistic mechanisms on asthma.

\section{Abbreviations \\ LBW: Low birth weight; HBW: High birth weight; SGA: Small for gestational age; LGA: Large for gestational age; BW/GA: Birth weight for gestational age; AGA: Appropriate for gestational age; OR: Odds ratio; Cl: Confidence intervals.}

\section{Acknowledgements}

Thanks to our grant providers.

\section{Authors' contributions}

JJW was responsible for methodology, data analysis, writing and submission. ZYZ contributed to the writing idea, data analysis and original draft writing. OC supervised and contributed to data analysis and writing. All authors have read and approved the final manuscript.

\section{Funding}

OC was supported by the Natural Science Foundation of Shandong Province (grant: ZR2020MH006) and the Key Technology Research and Development Program of Shandong Province (Grant: 2019GSF108198).

\section{Availability of data and materials}

The datasets used and analyzed during the current study can available from the corresponding author on reasonable request. 


\section{Declarations}

\section{Ethics approval and consent to participate}

The study does not require ethical approval because the meta-analysis is based on published research and the original data are anonymous.

\section{Consent for publication}

Authors are the sole responsible for the publication of this study.

\section{Competing interests}

Authors have no competing interests to declare.

Received: 8 March 2021 Accepted: 26 November 2021

Published online: 04 January 2022

\section{References}

1. Vos T, Flaxman AD, Naghavi M, Lozano R, Michaud C, Ezzati M, et al. Years lived with disability (YLDs) for 1160 sequelae of 289 diseases and injuries 1990-2010: a systematic analysis for the Global Burden of Disease Study 2010. Lancet (London, England). 2012;380(9859):2163-96.

2. Dharmage SC, Perret JL, Custovic A. Epidemiology of asthma in children and adults. Front Pediatr. 2019:7:246.

3. Subbarao P, Mandhane PJ, Sears MR. Asthma: epidemiology, etiology and risk factors. CMAJ. 2009;181(9):E181-90.

4. Kim A, Lim G, Oh I, Kim Y, Lee T, Lee J. Perinatal factors and the development of childhood asthma. Ann Allergy Asthma Immunol. 2018;120(3):292-9.

5. Gillman MW. Mothers, babies, and disease in later life. BMJ. 1995;310(6971):68-9.

6. Callaghan WM, Dietz PM. Differences in birth weight for gestational age distributions according to the measures used to assign gestational age. Am J Epidemiol. 2010;171(7):826-36.

7. Mu M, Ye S, Bai MJ, Liu GL, Tong Y, Wang SF, et al. Birth weight and subsequent risk of asthma: a systematic review and meta-analysis. Heart Lung Circ. 2014;23(6):511-9.

8. Halvorsen T, Skadberg BT, Eide GE, Røksund O, Aksnes L, Øymar K. Characteristics of asthma and airway hyper-responsiveness after premature birth. Pediatr Allergy Immunol. 2005;16(6):487-94.

9. Boney CM, Verma A, Tucker R, Vohr BR. Metabolic syndrome in childhood: association with birth weight, maternal obesity, and gestational diabetes mellitus. Pediatrics. 2005;115(3):e290-6.

10. Garite TJ, Clark R, Thorp JA. Intrauterine growth restriction increases morbidity and mortality among premature neonates. Am J Obstet Gynecol. 2004;191(2):481-7.

11. Malloy $\mathrm{MH}$. Size for gestational age at birth: impact on risk for sudden infant death and other causes of death, USA 2002. Arch Dis Child Fetal Neonatal Ed. 2007;92(6):F473-8.

12. Gessner BD, Chimonas MA. Asthma is associated with preterm birth but not with small for gestational age status among a populationbased cohort of Medicaid-enrolled children < 10 years of age. Thorax. 2007;62(3):231-6

13. Carter JH, Woolcott CG, Liu L, Kuhle S. Birth weight for gestational age and the risk of asthma in childhood and adolescence: a retrospective cohort study. Arch Dis Child. 2019;104(2):179-83.

14. Kallen B, Finnström O, Nygren KG, Otterblad OP. Association between preterm birth and intrauterine growth retardation and child asthma. Eur Respir J. 2013;41(3):671-6.

15. Miyake $Y$, Tanaka K. Lack of relationship between birth conditions and allergic disorders in Japanese children aged 3 years. J Asthma. 2013;50(6):555-9.

16. Jaakkola JJ, Gissler M. Maternal smoking in pregnancy, fetal development, and childhood asthma. Am J Public Health. 2004;94(1):136-40.

17. Begg CB, Mazumdar M. Operating characteristics of a rank correlation test for publication bias. Biometrics. 1994;50(4):1088-101.

18. Lu FL, Hsieh CJ, Caffrey JL, Lin MH, Lin YS, Lin CC, et al. Body mass index may modify asthma prevalence among low-birth-weight children. Am J Epidemiol. 2012;176(1):32-42.
19. Hesselmar B, Dahlgren J, Wennergren G, Aberg N, Albertsson-Wiklan K. Born small for gestational age: relation to future allergy and asthma. Acta Paediatr. 2002:91(9):992-4.

20. Wang WH, Chen PC, Hsieh WS, Lee YL. Joint effects of birth outcomes and childhood body mass index on respiratory symptoms. Eur Respir J. 2012;39(5):1213-9.

21. Grischkan J, Storfer-Isser A, Rosen CL, Larkin EK, Kirchner HL, South A et al. Variation in childhood asthma among former preterm infants. J Pediatr. 2004;144(3):321-6.

22. Liu X, Olsen J, Agerbo E, Yuan W, Cnattingius S, Gissler M, et al. Birth weight, gestational age, fetal growth and childhood asthma hospitalization. Allergy Asthma clin Immunol. 2014;10(1):13.

23. Pinto LA, Guerra S, Anto JM, Postma D, Koppelman GH, de Jongste JC, et al. Increased risk of asthma in overweight children born large for gestational age. Clin Exp Allergy. 2017;47(8):1050-6.

24. Koshy G, Akrouf KA, Kelly Y, Delpisheh A, Brabin BJ. Asthma in children in relation to pre-term birth and fetal growth restriction. Matern Child Health J. 2013:17(6):1119-29.

25. Hughes MM, Black RE, Katz J. 2500-g low birth weight cutoff: history and implications for future research and policy. Matern Child Health J. 2017;21(2):283-9.

26. Battaglia FC, Lubchenco LO. A practical classification of newborn infants by weight and gestational age. J Pediatr. 1967;71(2):159-63.

27. Osuchukwu OO, Reed DJ. Small for Gestational Age. StatPearls. Treasure Island (FL): StatPearls Publishing Copyright @ 2020 , StatPearls Publishing LLC.; 2020.

28. Lal MK, Manktelow BN, Draper ES, Field DJ. Chronic lung disease of prematurity and intrauterine growth retardation: a population-based study. Pediatrics. 2003;111(3):483-7.

29. Palta M, Sadek-Badawi M, Sheehy M, Albanese A, Weinstein M, McGuinness $G$, et al. Respiratory symptoms at age 8 years in a cohort of very low birth weight children. Am J Epidemiol. 2001;154(6):521-9.

30. Moore SE. Nutrition, immunity and the fetal and infant origins of disease hypothesis in developing countries. Proc Nutr Soc. 1998;57(2):241-7.

31. Been JV, Lugtenberg MJ, Smets E, van Schayck CP, Kramer BW, Mommers $M$, et al. Preterm birth and childhood wheezing disorders: a systematic review and meta-analysis. PLoS Med. 2014;11(1): e1001596.

32. Kumar R, Yu Y, Story RE, Pongracic JA, Gupta R, Pearson C, et al. Prematurity, chorioamnionitis, and the development of recurrent wheezing: a prospective birth cohort study. J Allergy Clin Immunol. 2008;121(4):878-84.e6.

33. Villamor E, lliadou A, Cnattingius S. Is the association between low birth weight and asthma independent of genetic and shared environmental factors? Am J Epidemiol. 2009;169(11):1337-43.

34. Schellong K, Schulz S, Harder T, Plagemann A. Birth weight and long-term overweight risk: systematic review and a meta-analysis including 643,902 persons from 66 studies and 26 countries globally. PloS ONE. 2012;7(10): e47776.

35. Strauss RS. Effects of the intrauterine environment on childhood growth. Br Med Bull. 1997;53(1):81-95

36. Steur M, Smit HA, Schipper CM, Scholtens S, Kerkhof M, de Jongste JC, et al. Predicting the risk of newborn children to become overweight later in childhood: the PIAMA birth cohort study. Int J Pediatr Obes. 2011;6(2-2):e170-8.

37. Litonjua AA, Gold DR. Asthma and obesity: common early-life influences in the inception of disease. J Allergy Clin Immunol. 2008;121(5):1075-84 (quiz 85-6).

38. Papoutsakis C, Priftis KN, Drakouli M, Prifti S, Konstantaki E, Chondronikola $\mathrm{M}$, et al. Childhood overweight/obesity and asthma: is there a link? A systematic review of recent epidemiologic evidence. J Acad Nutr Diet. 2013;113(1):77-105.

\section{Publisher's Note}

Springer Nature remains neutral with regard to jurisdictional claims in published maps and institutional affiliations. 